\title{
The Utility of Two National Injury Databases to Evaluate Snow-Sports Injuries in New Zealand
}

\author{
Brenda Costa-Scorse, Will G. Hopkins, John Cronin, and Eadric Bressel
}

\begin{abstract}
To accurately inform injury-prevention initiatives an in-depth evaluation of the utility of injury-incidence databases is essential. As part of development of a 5-year national injury-prevention strategy for snow sports in New Zealand, injury rates were compared in two databases: the Accident Compensation Commission (ACC) claims database of all snow-sports injuries treated by physiotherapists or doctors and the national incident database (NID) of injuries treated at all commercial ski areas. The ACC database focuses on treatment costs, whereas the NID database provides details of skier/boarder ability, terrain, surface condition, visibility, and equipment factors, all important information for developing injury-prevention interventions. The total injury rate in the ACC database was 8.8 injuries per 1000 skier/boarder days in the 2010 and 2011 winter seasons. The NID revealed that only one-third of these injuries were assessed and treated at mountain clinics. Sprains accounted for the greatest difference in injury rates between the ACC and the NID (5.3 and 1.3, respectively). Rates of all other main types of injury where higher in the ACC. This "bypass" effect likely represents a delay in seeking treatment that may be explained by increased swelling or pain after leaving the ski area. The bypass effect presumably applies to injury rates in all studies based solely on mountain-clinic incident data and needs to be taken into account when assessing injury trends and aetiology in alpine skiing and snowboarding.
\end{abstract}

Keywords Skiing $\bullet$ Snowboarding $\bullet$ Injury $\bullet$ Causation $\bullet$ Mechanisms $\bullet$ Prevention

\author{
B. Costa-Scorse $(\varangle) \cdot J$. Cronin \\ Sports Performance Research Institute New Zealand (SPRINZ), AUT University, \\ Auckland, New Zealand \\ e-mail: brenda.costa-scorse@aut.ac.nz \\ W.G. Hopkins • E. Bressel \\ Institute of Sport, Exercise and Active Living, Victoria University, Melbourne, Australia
}




\section{Introduction}

The development of the New Zealand snow sports injury-prevention strategy [1] provided the impetus to increase understanding of skiing and snowboarding injuries and apply discoveries made. Traditionally, the magnitude of the injury problem in alpine skiing and snowboarding was solely determined for Ski Areas Association New Zealand (SAANZ) using the national incident database (NID) database. NID analysis provided only one part of the picture, injured people that were assessed and treated at all commercial ski areas. To determine the true magnitude of the injury problem, the proportion and type of injuries that bypass mountain clinics then seek treatment off-the-hill needed to be determined. The Accident Compensation Commission (ACC) database provided all personal injury claims for snow sports; comparison of both the NID and ACC would provide a complete picture.

\section{Aims}

The primary aim of this study was to quantify the magnitude and nature of the injury problem in alpine skiing and snowboarding in New Zealand. The secondary aims were to determine the utility of two snow-sports injury databases and inform the development of a national injury-prevention strategy.

\section{Methods}

The NID incident reporting form was revised by the primary researcher and a SAANZ working group in the summer of 2010 prior to commencing NID data collection. Data collected at all ski areas was modified and expanded to include: resident or nonresident; free text space for description of the incident; fall, jump/landed, or slide; type of lift (chair-lift, Tbar, platter, ropetow, carpet lift, fixed grip tow); equipment ownership (self-owned, borrowed, rented on-hill, rented off-hill); equipment maintenance (binding calibration this season, $>1$ season, or never) and ski-binding release settings; skier height and weight; ski-binding release, no release, or premature release; and, terrain-park detail (box, jump, or rail). Activity, collision factors, visibility, snow conditions, protective equipment, and the injury code data points were retained unchanged. Ethics approval was gained from the Auckland University of Technology ethics committee (\#14146) and the ACC ethics committee (\#258). Descriptive epidemiological analyses and comparisons were made of ACC personal injury claimant data from the legislated government no-fault insurance scheme and the NID for incidents treated at all commercial ski areas 1 June to 31 October in 2010 and 2011. SAANZ provided population numbers for each season using ticket sales and season pass records. The ACC diagnosis, read code, and read code description data were used to group ACC data into the condition categories used in the NID. Analysis of the comprehensive cost details in the ACC data was not undertaken. 
Medical condition categories in the NID were not included. Both data sets were evaluated for completeness by undertaking checks of blank fields and missing codes.

Proportions of injuries and injury risk were analysed using Poisson or logistic regression. Analysis was performed with the Statistical Analysis System (SAS). Injury rates per 1000 skier days were determined using SAANZ population data. A factor of 0.82 was applied to ACC injury counts to remove injuries that occurred outside commercial ski areas and thereby, allow comparison with NID counts. The $p$ value for the difference of the rates was derived by assuming the normal approximation for the sampling distribution of the two proportions and by assuming (conservatively) the independence of the two proportions. The ratio of the proportions was assumed to have a log-normal sampling distribution, and the confidence limits for the ratio were derived from the $p$ value using a spreadsheet [2]. The magnitude-based inference to assess the uncertainty in the outcomes was also calculated in this spreadsheet. Proportion ratios of 0.90 and the inverse 1.11 were assumed to be the smallest clinically important ratios.

\section{Results}

The ACC database provided body part injured and diagnoses on 24,793 incident claims. The data required considerable checking, filtering, and manipulation to resolve inconsistencies in recording the nature and location of injuries. Missing data were found for $<2 \%$ of ACC cases; these blanks did not impact determination of a diagnosis. ACC incorrectly attributed $<0.01 \%$ of snow-sports injuries to waterskiing, jet-skiing, or wakeboarding. Free text written by the injured skier or snowboarder (claimant) describing the mechanism of injury were not thematically analysed as apart from "fall" there was no consistency in terms.

The NID provided comprehensive descriptive data on 7851 incidents. Skibinding release, non-release, and ski equipment servicing data were collected only in skiing knee and lower-leg injuries. Missing data were found for $<1 \%$ of NID cases; these blanks did not effect determination of a diagnosis. There were no differences in NID incident reporting practices at small ski areas staffed solely by ski patrollers when compared to large ski areas staffed by doctors, nurses, radiographers, and ski patrollers. Coding of injury severity was not consistent in the NID. For example, fractures that occurred in the same part of the body were either coded status three moderate or status four minor. Status codes were also problematic in three cases where minor injuries were incorrectly recorded at one ski area as deceased. A ski area manager corroborated the coding error. Mortality data from the Coronial Services of New Zealand confirmed the dates, times, and causes of three ski area fatalities (two skiers, one snowboarder). Two of three of these fatalities were recorded as status one critical, and the third fatality was not recorded.

The overall injury rate for the combined winter seasons 2010 and 2011 was 8.8 per 1000 skier/boarder days (ACC) and 3.2 per 1000 skier/boarder days (NID). Sprains accounted for the biggest difference in injury rate between the ACC and the 


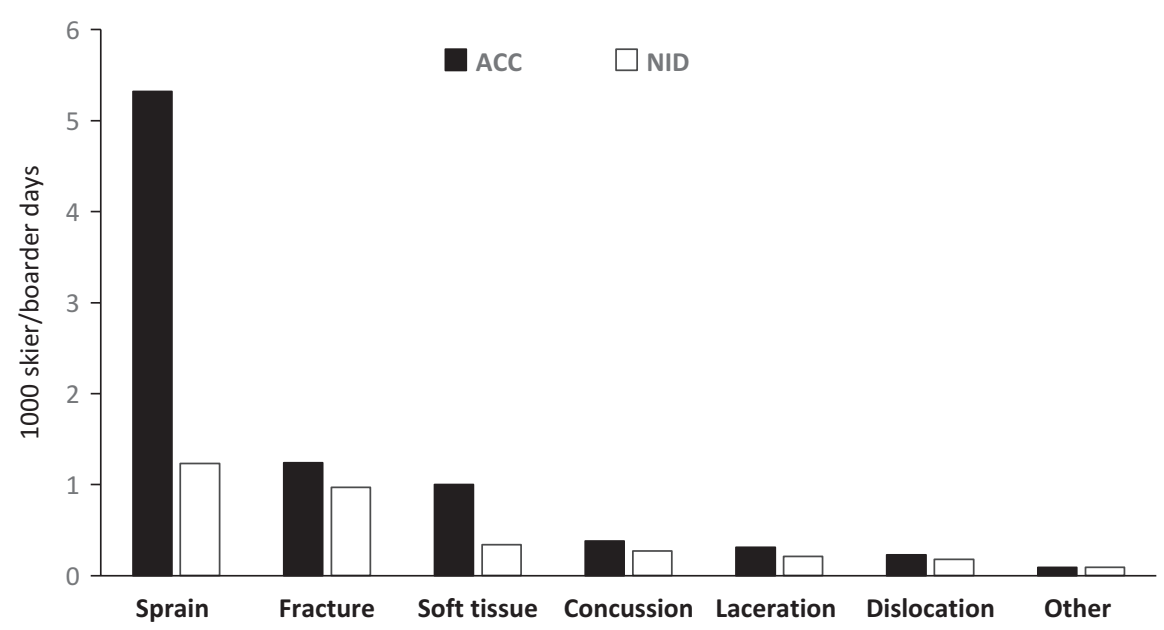

Fig. 1 ACC and NID comparison of injury type per 1000 skier/boarder days

NID (5.3 and 1.3, respectively). Figure 1 provides a graphic of the differences in all injury categories.

In comparing the injury counts per 1000 skier/boarder days for the ACC and NID shown in Fig. 1, sprains were 5.3 vs. 1.2 (ratio 4.3, 99\% confidence interval, confidence interval 4.2-4.5); fractures 1.2 vs. 1.0 (ratio 1.28, 1.19-1.36); soft tissue 1.0 vs. 0.34 (ratio $2.9,2.7-3.2$ ); concussion 0.38 vs. 0.27 (ratio $1.4,1.3-1.6$ ); lacerations 0.31 vs. 0.21 (ratio $1.5,1.3-1.7$ ); dislocation 0.23 vs. 0.18 (ratio $1.3,1.1-1.5$ ); and other injuries (burns, nerve injuries, foreign bodies, dental) 0.09 vs. 0.09 (ratio 1.0, 0.8-1.3). Internal injuries were extremely rare: 8 ACC cases and 15 NID cases, respectively.

The approximate proportion of the population active in each snow sport were: $61 \%$ skiers, $32 \%$ snowboarders, $7 \%$ both ski and snowboard. Skiers suffered more sprains than snowboarders (ACC $68 \%$ vs. 54\%; NID $48 \%$ vs. $28 \%$ ), less fractures (ACC $10 \%$ vs. $21 \%$; NID $21 \%$ vs. $38 \%$ ), and similar proportions of concussion (ACC $4 \%$ vs. $5 \%$; NID $8 \%$ vs. 9\%). The proportions of other injury categories were similar for skiers and snowboarder. Similar agreement between the ACC and the NID were found for body part injured. For example, sprains commonly involved the knee in skiers vs. snowboarders (ACC 33\% vs. 15\%, NID 54\% vs. 21\%), whereas snowboarders had more wrist fractures than skiers (ACC 54\% vs. 24\%, NID 57\% vs. $22 \%$ ). Sustaining a fracture of the lower leg remained the domain of skiers rather than snowboarders (ACC $16 \%$ vs. 3\%, NID 16\% vs. $2 \%$ ).

\section{Discussion}

The purpose of this study was to quantify the magnitude and nature of the injury problem in alpine skiing and snowboarding in New Zealand, determine the utility of two snow-sports injury databases, and inform the development of the national 
injury-prevention strategy [1]. An understanding of the coding, classifications, and terminology used in each database is the first requirement for undertaking a study that compares data [3]. ACC used a single diagnosis code for an individual claimant; multiple injuries were not captured in the code. The compact hierarchy of medical codes were developed by Dr. James Read in 1983 to cater for computer systems that had limited memory. Discordance relating to diagnosis may occur when assigning the Read code, and the code may also be applied incorrectly [4-7]. In New Zealand, there has been no systematic education for health professionals on how to use Read codes, this lack of education has added to concerns that diagnostic coding errors may occur [6]. However, missing diagnoses in the ACC database of $<2 \%$ would not be an issue for assessment of trends in injury incidence.

The NID used simplified diagnostic codes for up to three injuries for one individual, with a four part number and letter system for status, body part injured, side and condition. These nomenclatures added an element of sophistication and provided description of individual skiers or snowboarders who had multiple injuries. The small percentage of NID coding errors was seemingly typographical. Use of status 1 (critical problem with an immediate threat to life) as opposed to status 0 (dead) may have been due to patients being under resuscitation at the time of handover to the helicopter emergency medical service. Missing diagnoses in the NID database of $<1 \%$, as for the ACC, would not be an issue for assessment of trends in injury incidence.

Statistical methods have been designed to support comparison of injury incidence in studies of snow sports [8-11]. When comparing studies consideration needs to be given to the fact that some jurisdictions only include injuries that have been assessed and diagnosed by medical practitioners and other areas may only analyse ski patrol data. Depending on what data is entered into the incident database the number of injuries and patterns of injury may increase or decrease. Medical practitioner incident data may have less minor injuries than ski patrol data. For example, a skier suffering a minor laceration from a ski-edge may only require first aid, not require suturing, and therefore, will not see a doctor. In New Zealand, regardless of the staff skill mix lacerations were recorded as soft tissue injuries in the NID. This reporting culture may lead to an increased proportion of soft tissue injuries when compared with other studies. Importantly, there was no difference in accuracy of data entry when comparing small New Zealand ski areas staffed solely by ski patrollers and large ski areas staffed by a mixed medical team. These finding correlate with Canadian analysis of ski patrol information quality [12].

Norway has a central registry representing 53\% of skier/boarder days; 1.3 injuries per 1000 skier/boarder days occurred in the 2008/2009 and 2009/2010 seasons [13]. In a study of 10 French ski areas in 2007 and 2010, Laporte et al. [14] found that incident rates fell from 2.8 to 2.4 per 1000 skier/boarder days. Shealy et al. [15] found that the weighted US skiing incident rates in national ski areas association data declined from 3.1 in 1980 to 2.5 per 1000 visits in 2010. The NID incident rates for skiers and snowboarders treated at ski areas in New Zealand were higher than France, Norway, and the USA. 
The substantially higher injury rate in the ACC compared with the NID represents a "bypass effect". This effect is most likely due to evolving symptoms leading to first presentations occurring off-the-hill and the no-fault accident compensation system that covers personal claims. For example, symptoms of concussion may not develop immediately following an incident on the snow. Injured international skiers and snowboarders are unlikely to return home for first treatment as ACC covers treatment costs, and New Zealand is an international flight away from other countries. Ski areas located in large continents are likely to see bypass as injured skiers and snowboarders return to their state or country of origin, making it difficult to capture this group of injured.

The ACC system has been heralded as a world-leading solution when comparing medical systems that have burgeoning costs, but it has also been criticised for its potential for false claims by individuals who did not sustain an acute injury in the activity that was registered in the claim $[16,17]$. It seems unlikely that there would be a substantial misattribution of injuries to snow sports. However, the ACC system may promote claims for minor injuries where the individual in a user pays environment possibly would not seek treatment. Injured individuals can make a personal injury claim with a medical practitioner, physiotherapist, or other ACC accredited health provider. The choice of treatment modality may in-part explain higher injury rates in the ACC data. For example with universal insurance cover, a skier or snowboarder with back strain can present directly to a physiotherapist or chiropractor for assessment and treatment at no cost or a low cost surcharge and ACC will cover the remaining treatment costs. In other health systems, the back sprain incidence may be lower as skiers and snowboarders opt for self-management rather than registering as injured.

High proportions of knee sprains in skiing were found in recent epidemiological studies [13, 14, 18-20]. The large numbers of knee sprains bypassing mountain clinics in New Zealand highlight that the problem is greater than previously considered. Delays in seeking assessment and treatment for sprains can be explained by swelling evolving over time, increasing limitation of movement, and difficulty with managing pain. Grades of medial collateral ligament injury provide a possible explanation for bypassing mountain clinics [21]. Grade I knee injuries may be painful in the days after skiing but have no laxity and would probably not limit a skier getting off-the-hill without assistance. Grade II knee injuries involve separation of the collagen fibres of the medial collateral ligament, have partial laxity, and may involve the joint capsule, anterior and/or posterior cruciate ligament. Depending on the degree of disability and laxity, grade II medial collateral knee ligament injury may not present at mountain clinics or seek assistance from ski patrollers for extrication by toboggan. However, it is likely that grade II injured individuals would have difficulty getting on and off a chair-lift. Grade III medial collateral knee ligament injuries are a severe injury that would limit capacity to continue skiing. The complete rupture that occurs in a grade III injury, lax joint, and increased chance of haemathrosis would mean that this group of injured skiers would likely present to ski patrol on-the-hill. Skiers with grade I or grade II injuries possibly take a wait and see approach to see what level of disability exists in the days following skiing. There was no difference in the definition of a sprain in the NID and ACC coding that 
could lead to an alternative explanation for the high proportion of knee sprains in the ACC data.

Both databases indicated that fractures of the lower leg were more common in skiers than snowboarders. The sharp decline in lower-limb fractures seen after the invention of the dual-direction ski-binding in the 1970s and 1980s has not been sustained [22-24]. Poor ski-binding maintenance, incorrect release settings, ill-fitting ski boots, changes to skiing style, and skiers unprepared for the trajectory of the carving ski are possible explanations for the continued issue of fractures of the lower leg.

The ACC and the NID reported higher proportions of wrist fractures in snowboarders when compared to skiers; this is consistent with findings in other studies $[25,26]$. The mechanics of falling on an out-stretched hand and frequency of falling when snowboarding (particularly for novices) explains the difference in injury proportions [27]. Interventions to reduce the incidence of wrist fractures in snowboarders could include instruction on staying upright, instruction on how to fall, and increased use of wrist protectors [28].

The proportions represented by concussion in skiers and snowboarders were similar. Further research is needed to describe the nature of head injuries in skiers and snowboarders in New Zealand. In the interim, analysis of head injuries elsewhere has provided sufficient evidence for promoting the wearing of helmets [29-31].

\section{Conclusion}

Researchers informing the development of injury-prevention interventions should not rely solely on one injury database. Bypass injury rates are needed to determine the true magnitude of the injury problem in skiing and snowboarding. Insurance databases are a relatively blunt tool for determining behavioural, equipment, or environmental risk factors. Mountain-based epidemiological studies provide the detail required to inform injury-prevention initiatives. Increased understanding is needed on the demographic of skiers and snowboarders who delay seeking treatment, as early intervention may reduce severity and enhance recovery.

Acknowledgements The authors are grateful to SAANZ and ACC for supplying data. SAANZ are also acknowledged for their unequivocal encouragement during the development of the New Zealand Snow Sports Injury Prevention Strategy (2015-2020).

\section{References}

1. Costa-Scorse B, Hoyle A, Davidson M, Dooney A, Clinton-Baker P, Lamont M, Cronin J, Bressel E, Hopkins WG 2015 New Zealand snow sports injury prevention strategy (2015-2020)—a snow sports industry initiative. Ski Areas Association New Zealand

2. Hopkins WG, Marshall SW, Batterham AM, Hanin J (2009) Progressive statistics for studies in sports medicine and exercise science. Med Sci Sports Exerc 41(1):3-12 
3. de Lusignan S (2005) Codes, classifications, terminologies and nomenclatures: definition, development and application in practice. Inform Prim Care 13(1):65-69

4. Tilyard MW, Gurr E, Munro N, Walker SA, Dovey SM (1998) Creating a general practice national minimum data set: present possibility or future plan? N Z Med J 111(1072):317-320

5. Peat G, Greig J, Wood L, Wilkie R, Thomas E, Croft P (2005) Diagnostic discordance: we cannot agree when to call knee pain 'osteoarthritis'. Fam Pract 22(1):96-102

6. Hall J, Tomlin A, Martin I, Tilyard M (2002) A general practice minimum data set for New Zealand. N Z Med J 115(1163):U200

7. De Lusignan S, Stephens PN, Adal N, Majeed A (2002) Does feedback improve the quality of computerized medical records in primary care? J Am Med Inform Assoc 9(4):395-401

8. Johnson RJ, Ettlinger CF, Shealy JE (2003) A method for comparing alpine skiing injuries among studies. J ASTM Int 14(STP 1440):121-128

9. Lamont MK (1991) Ski injury statistics, what changes? J ASTM Int STP 1104:158-163

10. Knowles SB, Marshall SW, Guskiewicz KM (2006) Issues in estimating risks and rates in sports injury research. J Athl Train 41(2):207-215

11. Marshall SW (2008) Injury case-control studies using "other injuries" as controls. Epidemiology 19(2):277-279

12. Hagel BE, Pless IB, Goulet C, Platt RW, Robitaille Y (2004) Quality of information on risk factors reported by ski patrols. Inj Prev 10(5):275-279

13. Ekeland A, Rødven A (2012) Alpine skiing, telemarking, snowboarding, and skiboarding injuries related to gender and ability. J ASTM Int 2012:216-227

14. Laporte JD, Bajolle L, Lamy D, Delay JB (2012) Winter sports injuries in France over two decades. J ASTM Int 19(STP1553):201-215

15. Shealy J, Ettlinger CE, Scher I, Johnson R (2014) 2010/2011 NSAA 10-year interval injury study. J ASTM Int 20(STP1582):93111

16. Spearing NM, Connelly L (2011) Is compensation "bad for health"? A systematic meta-review. Injury 42(1): 15-24

17. Lichtenstein B (1999) From principle to parsimony: a critical analysis of New Zealand's nofault accident compensation scheme. Soc Justice Res 12(2):99-116

18. Laporte JD, Binet MH, Constans D (2000) Evolution of ACL ruptures in French ski resorts 1992-1999. J ASTM Int 13(STP 1397):95-107

19. Johnson RJ, Etlinger CE, Shealy JE (2008) Update on injury trends in alpine skiing. J ASTM Int 17(STP 1510):11-22

20. Sulheim S, Holme I, Rødven A, Ekeland A, Bahr R (2011) Risk factors for injuries in alpine skiing, telemark skiing and snowboarding — case-control study. Br J Sports Med 45(16):1303-1309

21. Cox JS (1979) Injury nomenclature. Am J Sports Med 7(3):211-213

22. Shealy JE, Ettlinger CF, Johnson RJ (2003) What do we know about ski injury research that relates binding function to knee and lower leg injuries? J ASTM Int 14(STP 1440):36-52

23. Greenwald R, Senner V, Swanson S (2001) Biomechanics of carving skis. Schweiz Z Sportmed Sporttraumatol 49(1):40-44

24. Ettlinger CF, Johnson RJ, Shealy JE (2003) Where do we go from here? J ASTM Int 14 (STP 1440):53-63

25. Dickson TJ, Terwiel FA (2011) Snowboarding injuries in Australia: investigating risk factors in wrist fractures to enhance injury prevention strategies. Wilderness Environ Med 22(3): 228-235

26. Bianchi G, Michel FI, Brügger O (2012) The use of wrist guards by snowboarders in Switzerland. J ASTM Int STP 1553:38-53

27. Cooper N, Greenwald R (2006) Observational study on fall trends in snowboarding. J ASTM Int 3(5): 19-25

28. Michel FI, Schmitt KU, Greenwald RM, Russell K, Simpson FI, Schulz D, Langran M (2013) White paper: functionality and efficacy of wrist protectors in snowboarding-towards a harmonized international standard. Sports Eng 16(4):197-210

29. Scher I, Richards D, Carhart M (2006) Head injury in snowboarding: evaluating the protective role of helmets. J ASTM Int 3(4):JAI14203 
30. Ruedl G, Sommersacher R, Woldrich T, Kopp M, Nachbauer W, Burtscher M (2010) Risk factors of head injuries on Austrian slopes. German J Sports Med 61(4):97-102

31. Russell K, Christie J, Hagel BE (2010) The effect of helmets on the risk of head and neck injuries among skiers and snowboarders: a meta-analysis. Can Med Assoc J 182(4):333-340

Open Access This chapter is distributed under the terms of the Creative Commons AttributionNoncommercial 2.5 License (http://creativecommons.org/licenses/by-nc/2.5/) which permits any noncommercial use, distribution, and reproduction in any medium, provided the original author(s) and source are credited.

The images or other third party material in this chapter are included in the work's Creative Commons license, unless indicated otherwise in the credit line; if such material is not included in the work's Creative Commons license and the respective action is not permitted by statutory regulation, users will need to obtain permission from the license holder to duplicate, adapt or reproduce the material.

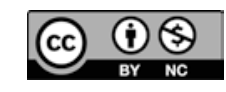

